\title{
KINERJA ROTATED CODED 8 PSK PADA KANAL RAYLEIGH
}

\section{PERFORMANCE OF ROTATED CODED 8 PSK IN RAYLEIGH CHANNELS}

\author{
Linda Meylani ${ }^{1}$, Nur Andini ${ }^{2}$, Iswahyudi Hidayat ${ }^{3}$, Hurianti Vidyaningtyas $^{4}$ \\ 1,2,3,4 Fakultas Teknik Elektro, Universitas Telkom, Jl. Telekomunikasi no 1, Bandung \\ lindameylani@telkomuniversity.ac.id,nurandini@telkomuniversity.ac.id, \\ iswahyudihidayat@telkomuniversity.ac.id, huriantividyaningtyas@telkomuniverisy.ac.id
}

\begin{abstract}
Abstrak
Diversitas ruang sinyal merupakan salah satu teknik yang dapat digunakan untuk meningkatkan kinerja sistem tanpa menggunakan error control coding, meningkatkan daya transmisi ataupun menurunkan data rate. Teknik diversitas ruang dapat dilakukan dengan melakukan rotasi pada konstelasi sinyal. Paper ini bertujuan untuk meningkatkan kinerja MC-CDMA dengan menggabungkan skema coded modulation 8 PSK dan skema rotasi. Berdasarkan hasil simulasi, diperoleh bahwa pada kanal fading skema rotated modulation dan coded modulation memberikan adanya perbaikan kinerja pada sistem MC-CDMA, namun pada kanal AWGN, perbaikan kinerja hanya ditunjukkan oleh penggunaan coded modulation.
\end{abstract}

\section{Kata kunci : rotated modulation, 8 PSK coded modulation, MC CDMA}

\begin{abstract}
Signal space diversity is a one of techniques to increase the performance of system without using error control coding technique, adding power transmission or reduce data rate but with rotate the signal constellation. With the aim to increase performance of MC CDMA, this paper combine rotated and trellis 8 PSK coded modulation scheme. From the simulation results, rotated modulation doesn't give any coding gain to system in AWGN channel, the performance of rotate modulation scheme and system MC CDMA without rotate scheme was relative have same performance. Different things happened in fading channel. Rotated modulation scheme give a better performance rather than system without rotate scheme. Coded modulation in the other side give a coding gain to the system in AWGN channel or in Rayleigh fading channel.
\end{abstract}

Keywords: rotated modulation, 8 PSK coded modulation, MC CDMA

\section{PENDAHULUAN}

Pemilihan skema modulasi dan teknik error control coding akan menentukan kinerja sistem komunikasi. Ketika sistem menggunakan skema modulasi dengan data rate yang tinggi, untuk mendapatkan kinerja sistem yang baik maka system membutuhkan adanya penggunaan skema error control coding untuk mengurangi terjadinya kesalahan pada informasi yang diterima. Penggunaan error control coding disisi lain membutuhkan penambahan daya transmisi. Hal ini dikarenakan adanya bit-bit redundancy yang ditambahkan untuk kebutuhkan koreksi error. Beberapa penelitian telah dilakukan untuk meningkatkan kemampuan modulasi dan pengkodean. Ungerboeck pengusulkan skema coded modulation yang menawarkan ketahanan dan kehandalan dengan melakukan kombinasi antara modulasi dan error control coding tanpa adanya tambahan daya transmisi ataupun menurunkan data rate sistem [1][2]. Coded modulation bekerja dengan mengkombinasikan teknik error control coding (dengan coding rate $\mathrm{k} /(\mathrm{k}+1)$ ) dan modulasi $\left(2^{\mathrm{k}+1}\right.$ level). Untuk memdapatkan coding dain pada kanal fading, Jouseph Boutros dan Emanuele Viterbo memperkenalkan penggunaan diversitas ruang sinyal [3]. Kunci diversitas ruang sinyal atau diversitas modulasi adalah melakukan rotasi pada konstelasi simbol pada ruang sinyal. Kanal fading mempengaruhi komponen sinyal terima yang mengubah konstelasi sinyal. Akibat fenomena 
ini umumnya pada kanal fading kinerja system menjadi menurun ditunjukkan dengan semakin besarnya nilai BER. Boutros and Viterbo [3] menunjukkan bahwa rotasi pada konstelasi sinyal akan mampu memperbaiki kinerja sistem.

Penelitian pada trellis code modulation (TCM) dan rotated modulation (RM) telah cukup banyak dilakukan. Beberapa diantaranya adalah Zehavi [4] dan Xiaodong [5] yang menambahkan blok interleaver pada TCM untuk meningkatkan coding gain pada kanal fading Rayleigh. Jian Liu [6] mengusulkan least significant bit block coding pada modulasi 8PSK dan menggunakan proses pemetaan dengan partisi dan menggunakan hard decision decoding. Sergio [7] menganalisa kinerja TCM, Fabian [8] menggunakan puncture decoding pada TCM. Zafar Ali Khan dan Sundar Rajan pada [9] menunjukkan bahwa TCM asimetris dengan 4 state dapat meningkatkan kinerja TCM pada kanal Fading Rayleigh. Misra [10] melakukan proses decoding TCM dengan menggunakan metode ant neural network (ANN), sedangkan Samreen Amir [11] dan Khairunnisa [12] menunjukkan kinerja TCM pada sistem MCCDMA ketika melewati kanal fading.

Penggunaan skema rotated modulation (RM) pada system OFDM diusulkan oleh Zhanji Wu [13]. Pada papernya, Zhanji Wu menggunakan turbo coding dan menambahkan blok interleaver sebelum proses rotasi konstelasi sinyal. Sistem yang diusulkan oleh Zhanji Wu memiliki kinerja yang lebih baik dibandingkan dengan skema bit interleave coded modulation (BICM). Zhanji Wu also improve the performance of rotated modulation in OFDM system by using iterative decoding in the receiver [14]. Analisa kinerja (RM) pada modulasi M-PSK juga dilakukan Ozyurt [15] pada kanal ricean. [15] menunjukkan bahwa sudut rotasi optimal yang digunakan tidak dipengaruhi oleh factor ricean $\mathrm{K}$, tetapi coding gain akan meningkat ketika factor $\mathrm{K}$ bernilai kecil.

Paper ini bertujuan untuk menganalisa kinerja system MCCDMA ketika mengkombinasikan skema rotated modulation (RM) dan trellis coded modulation (TCM) 8 PSK. Hal yang berbeda yang ditunjukkan pada paper ini adalah skema rotasi yang dilakukan. Pada paper ini terdapat dua blok interleaver yang digunakan pada quadrature dan inphase.

Stuktur penulisan pada paper ini dibagi dalam beberapa bab, baba I berisi pendahuluan, bab II akan membahas mengenai system model, bab III membahas mengenai hasil simulasi sedangkan bab IV menyatakan kesimpulan dari paper ini.

\section{SISTEM MODEL}

Model system dari skema kombinasi skema rotated-coded modulation (RCM) 8PSK ditunjukkan pada Gambar 1.

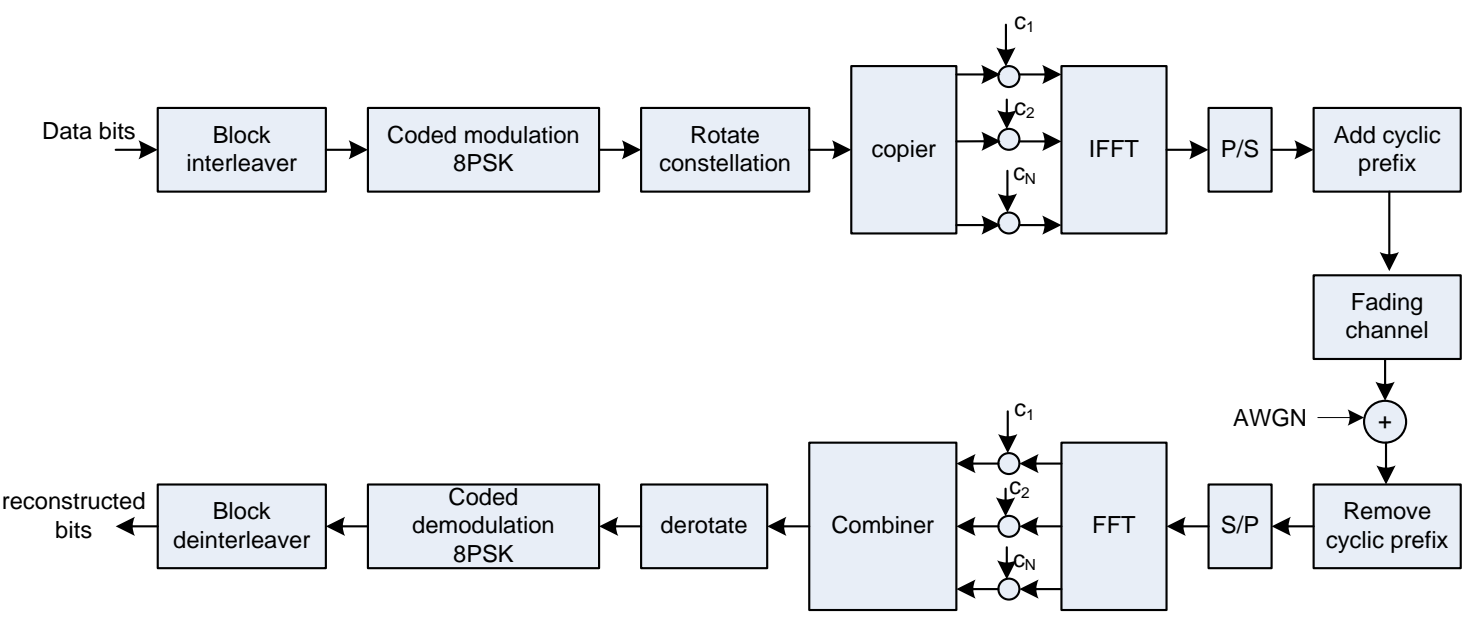

Gambar 1 Rotated-coded modulation 8 PSK pada sistem MCCDMA

Pada paper ini, skema coded modulation (CM) yang digunakan sama seperti yang digunakan pada [16]. Bit-bit keluaran dari blok interleaver dibagi menjadi 2 grup. Kelompok grup 
yang pertama akan menjadi input untuk blok interleaver pada CM. Grup kedua akan menjadi input bagi blok forward error correcting. Pada paper ini digunakan kode konvolusi dengan rate $1 / 2$ dan akan diacak kembali melalui interleaver. Setelash kedua grup bit melewati blok interleaver , maka bit output akan digabungkan kembali sebagai input bagi modulasi 8PSK. Proses coded modulation (CM) ditunjukkan pada gambar 2. Proses mapping pada CM dibagi dalam 3 langkah yaitu melakukan partisi set, langkah kedua pemilihan kode dan langkah ketiga adalah pemilihan subset. LSB dari setiap symbol akan digunakan untuk membagi subset menjadi 2 grup subset, yaitu subset"1", dan subset"0".

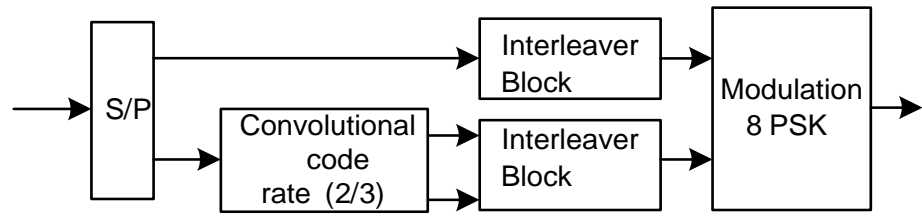

Gambar 2 Proses coded modulation (CM)

Jouseph Boutros dan Emanuele Viterbo pada [3] menggunakan gray mapping untuk melabel titik konstelasi. Namun pada paper ini digunakan natural binary mapping untuk melalbelkan output CM. Skema rotated modulation (RM) dilakukan dengan merotasi titik konstelasi. Beda phasa minimum antara dua symbol yang berdekatan pada 8PSK adalah $\pi / 4$, maka skema pergeseran phasa yang digunakan pada proses rotasi pada paper ini didesaign kurang dari $\pi / 8$ untuk menghindari kesalahan deteksi. Konstelasi klasik 8PSK dan konstelasi 8PSK setelah dirotasi ditunjukkan pada Gambar 3. Jika diasumsikan terjadi fading dan mengenai satu atau dua komponen dari simbol (quadrature atau inphase dari symbol), maka minimum akan ada empat titik konstelasi yang akan rusak pada konstelasi klasik 8PSK. Hal yang berbeda ditunjukkan pada konstelasi 8PSK yang dirotasi, hal ini disebabkan setiap komponen pada 8PSK yang dirotasi tidak memiliki kesamaan jalur. Proses RM ditunjukkan pada Gambar 4. Blok interleaver yang digunakan pada komponen inphase dan quadrature memiliki ukuran blok uyang berbeda.

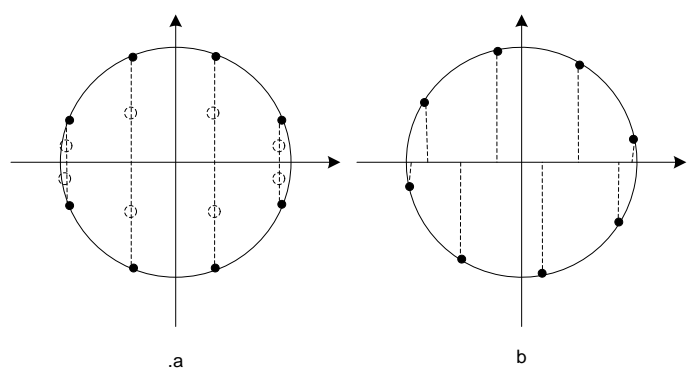

Gambar 3 Konstelasi PSK: (a) klasikal (b) Terrotasi

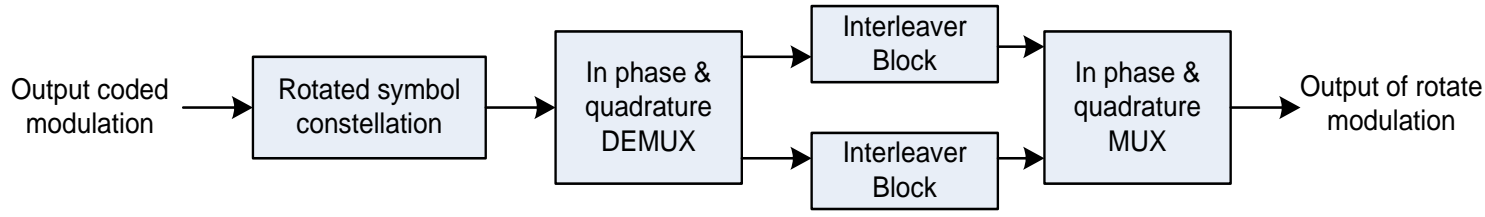

Gambar 4 Proses rotated modulation

Proses pendekodean pada RCM dilakukan dalam 2 tahapan proses. Tahap pertama adalah melakukan proses derotasi. Tahap kedua merupakan proses coded demodulation. Proses derotasi dibutuhkan untuk mengubah formasi sinyal terotasi ke dalam bentuk konstelasi coded modulation.

\subsection{Proses decoding RM}

Proses pendekodean sistem rotated modulation, umumnya menggunakan maximum 
likelihood decoding untuk mendapatkan simbol terdekodekan, dimana simbol-simbol ini akan dibandingkan dengan simbol referensi. Sistem akan menyatakan simbol yang diterima sebagai simbol terdekodekan jika simbol yang diterima memiliki nilai minimum seperti yang ditunjukkan pada persamaan (1)

$$
m(x \mid r)=\sum_{i=0}^{n}\left|\left(r_{i}-x_{i}\right)\right|^{2}
$$

Pada sistem yang diusulkan dimana skema rotated modulation dan coded modulation digabungkan. Proses decoding yang dilakukan pada blok RM hanya melakukan perubahan kembali ke bentuk awal konstelasi.

\subsection{Proses decoding CM}

Proses demodulate pada CM dilakukan dalam 2 tahap, yaitu mendefinisikan subset pada tahap pertama dan mendefinisikan komponen bit dalam subset sebagai tahap kedua dari proses demodulasi. Untuk menentukan bit tersisa apakah termasuk dalam subset "1" ataupun subset "0" dengan menggunakan algoritma log likelihood ratio (LLR). Simbol yang diterima oleh receiver dapat dinyatakn sebagai $\mathrm{r}=\mathrm{s}+\mathrm{n}$, dimana $\mathrm{n}$ meupakan noise gaussian dengan mean bernilai nol dan variansi noise dinyatakan dengan $\sigma^{2}$. LLR dapat didefinisikan sebagai berikut [16], [17]:

$$
\Lambda^{(i)}(r)=\ln \frac{\operatorname{Pr}\left\{r \mid b^{(i)}(r)=0\right\}}{\operatorname{Pr}\left\{r \mid b^{(i)}(r)=1\right\}}=\ln \frac{\sum_{s_{k} \in x_{0}(i)} p\left(r \mid s_{k}\right)}{\sum_{s_{k} \in x_{1}(i)} p\left(r \mid s_{k}\right)}
$$

Dimana $i \in\{1,2, \ldots, m\}$ dan $b^{(i)}(s)$ sebagai bit ke-I dari subset dan $\mathrm{p}\left(\mathrm{r} \mid \mathrm{s}_{\mathrm{k}}\right)$ merupakan conditional probability dari symbol terima ketika transmitter mengirimkan simbol $s_{k}$ dan terdapat noise AWGN.

Tabel 1. Parameter sistem

\begin{tabular}{|l|l|}
\hline Teknik error control & Kode konvolusi (1/2) hard decision \\
\hline & TCM $(2 / 3)$ \\
\hline Jumlah subcarrier & 64 \\
\hline Modulasi & 8 PSK \\
\hline Skema Akses & MC CDMA \\
\hline Model kanal multipath & Rayleigh \\
\hline Jumlah path & 2 \\
\hline Pergeseran phasa & $\pi / 16+(\mathrm{k} x \pi / 32)$ \\
\hline Skema simulasi & Tanpa rotated coded modulation $(\mathrm{RCM})$ \\
\hline & Dengan coded modulation $(\mathrm{CM})$ \\
\hline & Dengan rotated modulation $(\mathrm{RM})$ \\
\hline & Dengan rotated coded modulation (RCM) \\
\hline
\end{tabular}

\section{ANALISA KINERJA}

Analisa kinerja system dilakukan pada kanal AWGN dan fading.

\subsection{Kinerja rotated coded modulation (RCM) pada kanal AWGN}

Gambar 5 menunjukkan kinerja system MCCDMA menggunakan RCM dibandingkan dengan sistem MCCDMA dengan CM, RM dan tanpa RCM. 


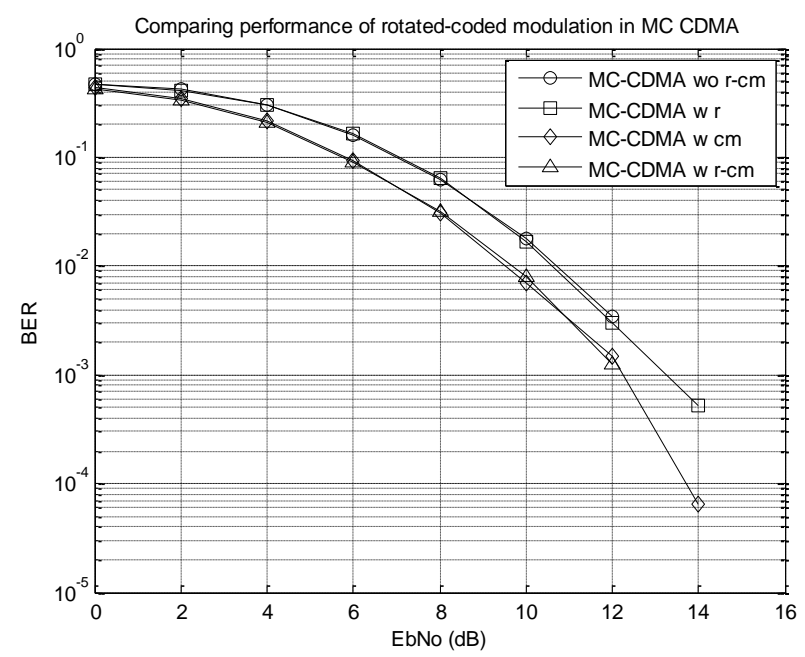

Gambar 5 Kinerja rotated coded modulation-MC CDMA pada kanal AWGN

Dari gambar 5 terlihat bahwa pada kanal AWGN, kinerja CM dan RCM relatif sama. Keduanya memberikan perbaikan kinerja bagi sistem MC CDMA bila dibandingkan dengan sistem MC CDMA tanpa RCM. Sistem MC CDMA-CM ataupun MC CDMA-RCM hanya membutuhkan Eb/Io yang lebih rendah dibandingkan sistem MCCDMA tanpa RCM. Untuk target BER $10^{-3}$, system MC CDMA-CM dan MC CDMA-RCM membutuhkan 1.2dB lebih rendah dibandingkan MC CDMA tanpa RCM. Hal yang berbeda ditunjukkan oleh skema RM pada sstem MCCDMA. Terlihat bahwa RM tidak menunjukkan adanya perbaikan kinerja bila dibandingkan terhadap sistem MC CDMA tanpa RCM. Hal ini mungkin dipengaruhi oleh kanal AWGN itu sendiri, dimana pada kanal AWGN, noise hanya ditambahkan pada siyal terima tetapi tidak mengubah konstelasi sinyal, sehingga penggunaan RM pada sistem MC CDMA tidak memberikan pengaruh pada kinerja sistem. Perbaikan kinerja yang ditunjukkan oleh CM dan RCM pada sistem MC CDMA juga tak lepas dari penggunaan skema pendekodean soft decision pada TCM.

\subsection{Kinerja Rotated Coded Modulation pada kanal fading Rayleigh}

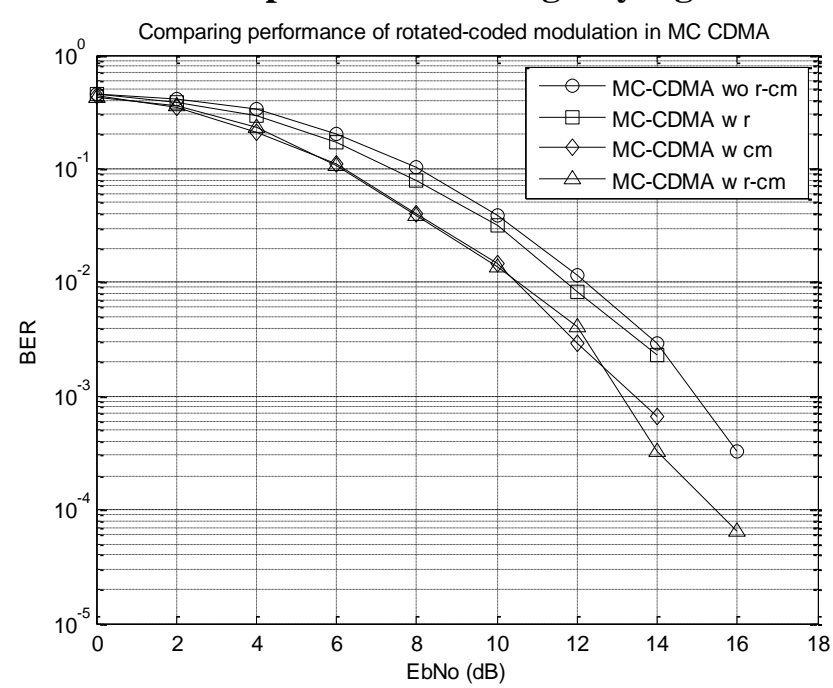

Gambar 6 Perbandingan kinerja RM, CM, dan RCM pada kanal fading Rayleigh (v=60km/hour,k=-0.75)

Gambar 6 dan 7 menunjukkan kinerja MCCDMA-RCM pada nilai k yang sama $(\mathrm{k}=-0.75)$ namun pada kondisi kecepatan yang berbeda. Untuk $\mathrm{k}=-0.75$ dan $\mathrm{v}=60 \mathrm{~km} / \mathrm{jam}$ sistem MCCDMA RCM dan MCCDMA- CM dapat mencapai BER 10-3 pada Eb/Io 13 dB. Pada kondisi kecepatan yang lebih rendah perbaikan kinerja yang ditunjukkan oleh MC CDMA-RM lebih kecil bila 
dibandingkan dengan perbaikan kinerja MC CDMA-RM pada kondisi kecepatan $120 \mathrm{~km} / \mathrm{jam}$. Namun untuk mencapai BER $10^{-3}$, MC CDMA-RM pada v=60km/jam membutuhkan Eb/Io yang lebih rendah $(13 \mathrm{~dB})$ dibandingkan system MC CDMA-RM pada $\mathrm{v}=120 \mathrm{~km} / \mathrm{jam}(15 \mathrm{~dB})$. Hal ini dikarenakan pada kecepatan yang lebih tinggi, daya sinyal terima jauh lebih lebih berfluktuasi. Adanya perbaikan kinerja yang ditunjukkan oleh CM, RM dan RCM pada system MC CDMA menunjukkan bahwa efek fading pada simbol terima dapat ditangani oleh RM. Dan kombinasi RM dan CM pada skema RCM menjadikan kinerja sistem MCCDMA menjadi lebih baik.

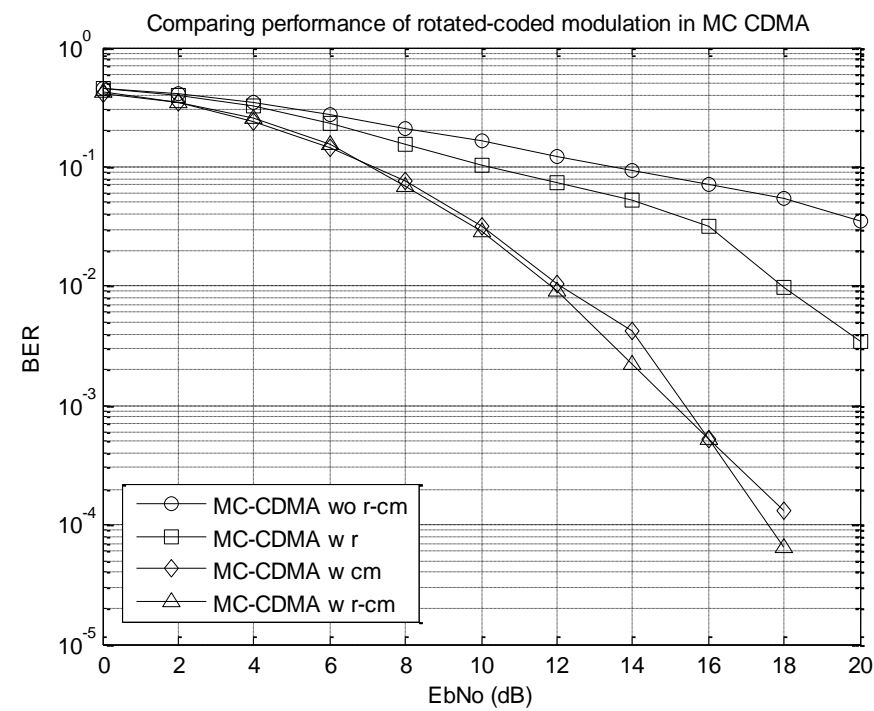

Gambar 7 Perbandingan kinerja RM, CM dan RCM pada kanal fading rayleigh (v=120km/hour, k=-0.75)

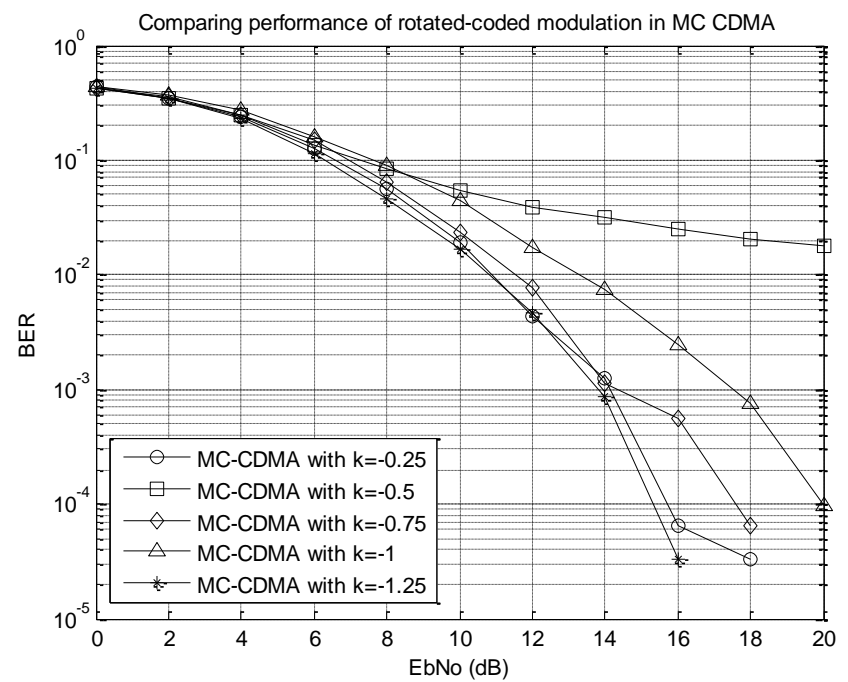

Gambar 8 Perbandingan variabel phase shifting k pada RCM (v=60km/hours, k negatif) 


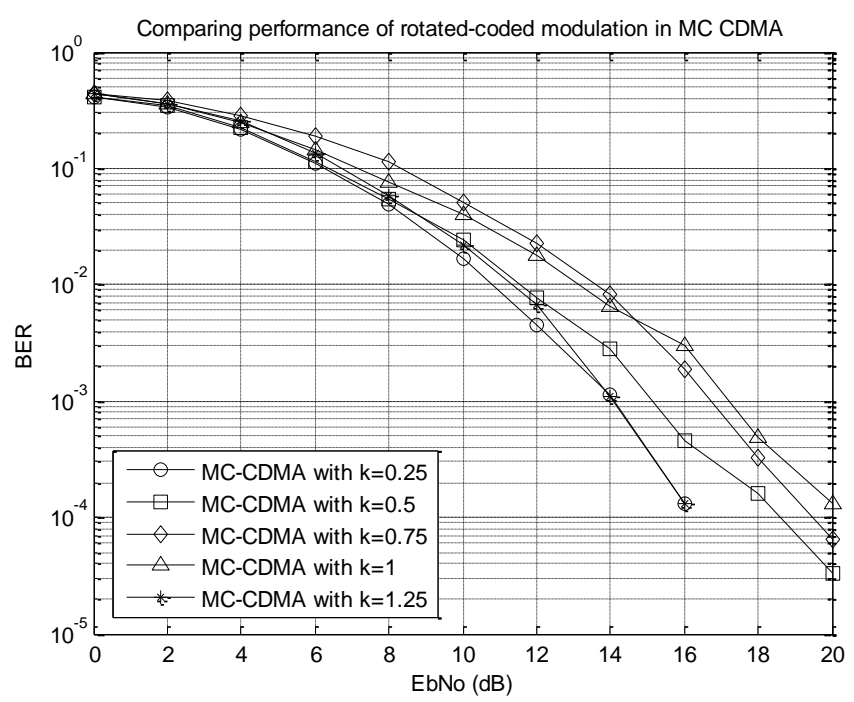

Gambar 9 Perbandingan variabel phase shifting k pada $\mathrm{RCM}$ ( $\mathrm{v}=60 \mathrm{~km} / \mathrm{hours}, \mathrm{k}$ positif)

Gambar 9 dan 10 menunjukkan pengaruh pergeseran phasa yang disebabkan oleh perubahan nilai $\mathrm{k}$ terhadap kinerja system MC CDMA. Nilai positif atau negatif yang diberikan pada variabel $\mathrm{k}$ menunjukkan respon yang berbeda pada sistem. Nilai negatif pada $\mathrm{k}$ memberikan perbaikan lebih pada sistem. Ketika k bernilai negatif phasa rotasi yang didapat lebih kecil dibandingkan dengan $\mathrm{k}$ bernilai positif dan menghasilkan konstelasi sinyal yang memiliki phasa antar simbol yang lebih besar dibandingkan ketika sistem menggunakan $\mathrm{k}$ bernilai positif. Nilai $\mathrm{k}=-1.25$ dari hasil simulasi menunjukkan kinerja yang paling baik dibandingkan dengan nilai $\mathrm{k}$ lain.

\section{KESIMPULAN}

Dari hasil simulasi terlihat bahwa skema coded modulation (CM) dan rotated coded modulation (RCM) memberikan perbaikan kinerja pada kondisi kanal AWGN ataupun Rayleigh fading. Namun skema rotated hanya pemberikan perbaikan kinerja pada kanal fading. Penggunaan phase shifting pada skema RCM akan menentukan kinerja sistem.

\section{DAFTAR PUSTAKA}

[1] G. Ungerboeck. Trellis-Coded Modulation with Redundant Signal Sets Part I: Introduction. IEEE Communications Magazine. 1987: 5-11.

[2] G. UngerboeckTrellis-coded modulation with redundant signal sets Part II: State of the Art. IEEE Communications Magazine, 1987: 25(2); 12-21.

[3] J. Boutros and E. Viterbo. Signal Space Diversity: A Power- and Bandwidth-Efficient Diversity Technique for the Rayleigh Fading Channel. IEEE Transaction on Information Theory.1998: 44(4); 1453-1467.

[4] E. Zehavi. 8-PSK trellis codes for a Rayleigh fading channel. IEEE Trans. Commun.1992: 40( 5); 873-883.

[5] X. Li, A. Chindapol, and J. A. Ritcey. Bit-Interleaved Coded Modulation With Iterative Decoding and 8PSK Signaling. IEEE Trans. Commun. 2002: 50(8); 1250-1257.

[6] J. Liu, S. C. Kwatra, and J. Kim. LSB coded 8PSK Signals. IEEE Trans. Commun.1995: 43(2); 151-153.

[7] S. Benedetto, S. Member, and G. Montorsi. Performance Evaluation of Trellis-Coded 
Modulation Schemes. Proc. IEEE.1994: 82(6); 833-855.

[8] F. Schuh, A. Schenk, and J. B. Huber. Punctured Trellis-Coded Modulation. Arxiv:1301.4050. 2013.

[9] Z. A. Khan and B. S. Rajan. A 4-State Asymmetric 8-PSK TCM Scheme for Rayleigh Fading Channels Optimum at High SNR. Vehicular Technology Conference Proceeding. 2000: 685-689.

[10] A. Misra and K. K. Sarma. TCM-coded OFDM assisted by ANN in Wireless Channels. Int. J. Smart Sensors Ad Hoc Networks. 2012: 1(3); 50-55.

[11] S. Amir and M. Asif. Analytical Study of MC-CDMA-TCM over Multi-path Rayleigh Fading Channels. IPCSIT.2011: 2; 332-337.

[12] A. K. Suharja, R. P. Astuti, L. Meylani and A. Fahmi, Enhancment of MC-CDMA Performance System Using Rotated Modulation, IEEE International Conference on Communication, Networks and Satellite, Surabaya, Indonesia, pp. 14-17, Dec. 2016

[13] Z. Wu, T. Fu, X. Wang, Y. Gao, C. Ma, and W. Wang. A Novel Coding Rotated Modulation OFDM Scheme. Proceeding of ICCTA. 2009: 517-520.

[14] W. Z. P. M. W. Wenbo. Improved coding-rotated-modulation orthogonal frequency division multiplexing system. IET Communications. 2012: 6(3); 272-280.

[15] S. Ozyurt, O. Kucur, and I. Altunbaa. Performance of Rotated Phase Shift Keying Modulation over Ricean Fading Channels. 2nd International Symposium on Wireless Communication Systems. 2005: 195-199.

[16] L. Meylani, N. Andini, and I. Hidayat. Performance of Coded Modulation in Multicarrier CDMA System. Indonesian Journal of Electrical Engineering and Computer Science. 2016: 1(3); 583-589.

[17] L. Wang, D. Xu, and X. Zhang. Recursive bit metric generation for PSK signals with gray labeling. IEEE Communication Letter. 2012: 16(2); 180-182.

[18] S. Ryoo, S. Kim, and S. P. Lee. Efficient Soft Demapping Method for High Order Modulation Schemes. CDMA International Conference. 2003: 2-6. 